\title{
PROCESSOS DE ACUMULAÇÃO CAPITALISTA E CONFLITOS TERRITORIAIS NO CERRADO
}

\author{
Glauber Lopes Xavier ${ }^{1}$ \\ Eliesse dos Santos Teixeira Scaramal ${ }^{2}$ \\ Mary Anne Vieira Silva ${ }^{3}$
}

\begin{abstract}
Resumo: Cumpre apreender que o processo de acumulação capitalista e os conflitos territoriais aqui discutidos ligam-se diretamente ao fenômeno do neocolonialismo, o qual provoca intensas ações de violência contra a população indígena e as Comunidades Tradicionais, sobremaneira as vivenciadas nos países latino-americanos nas últimas décadas. Para tanto, ocupa-se de tal realidade com base no cerrado brasileiro. Conformado pela violência contra povos indígenas e comunidades tradicionais quilombolas, geraizeiros (moradores do cerrado ao norte de Minas Gerais), vazanteiros (povos ribeirinhos que vivem no cerrado às margens dos rios São Francisco, Tocantins e Araguaia), bem como outras que se organizam e sobrevivem do trabalho familiar, o cerrado tem sido alvo de grandes empreendimentos capitalistas encetados a partir de uma geopolítica que se ancora na ocupação e gestão dos territórios em países pobres ou em desenvolvimento.
\end{abstract}

Palavras-chave: Neocolonialismo; violência; povos cerradeiros

Abstract: It should apprehend that the process of capitalist accumulation and discussed herein territorial conflicts bind directly to the neo-colonialism of the phenomenon, which causes intense acts of violence against indigenous people and traditional communities, greatly experienced in the Latin American countries in recent decades . Therefore, deals with this reality based on the brazilian cerrado. Shaped by violence against indigenous peoples and traditional communities, geraizeiros (cerrado residents north of Minas Gerais), vazanteiros ( riverine people living in the savanna along the rivers San Francisco, Tocantins and Araguaia) and others that are organized and surviving family work, the cerrado has been the target of large capitalist enterprises initiated from a geopolitical that is anchored in the occupation and management of territories in poor or developing countries.

Keywords: Neo-Colonialism; violence; cerradeiros people

\footnotetext{
Professor Adjunto da Universidade Estadual de Goiás. Vinculado ao Programa de Pós-Graduação Stricto Sensu em Territórios e Expressões Culturais no Cerrado (TECCER/UEG).Email: glauber.xavier@ueg.br

2 Professora Adjunta da Universidade Federal de Goiás. Email: eliessescaramal@terra.com.br

3 Professora Adjunta da Universidade Estadual de Goiás. Vinculada ao Programa de Pós-Graduação Stricto Sensu em Territórios e Expressões Culturais no Cerrado (TECCER/UEG). Email: marymel2006@hotmail.com
} 


\section{SOBRE O NEOCOLONIALISMO E A GEOPOLÍTICA DO CAPITAL NOS PAÍSES POBRES OU EM DESENVOLVIMENTO}

As reflexões a serem aqui tecidas fazem referência à um vertiginoso processo de mudanças ocorridas no cerrado ${ }^{4}$ brasileiro advindas de uma geopolítica internacional do capital. Entende-se que este fenômeno, o qual extrapola a questão econômica, configura um neocolonialismo nos países pobres, bem como em países em vias de desenvolvimento. A própria dinâmica econômica numa perspectiva global aponta para um rearranjo espacial das atividades produtivas, incorrendo em articulações territoriais a fim de assegurar determinada taxa de lucro, dada a ampla concorrência empresarial e a necessidade de redução de custo das mercadorias. Por outro lado, tais transformações dizem respeito às estratégias que envolvem estados-nações em seus projetos de médio e longo prazos, instaurando, assim, um novo modelo de imperialismo sobre tais países, como Índia, África do Sul e Brasil.

Os conflitos socioterritoriais que têm ocorrido e têm se ampliado nos últimos anos no cerrado, segundo maior bioma brasileiro, deslindam essa dinâmica capitalista e impõe a necessidade de investigações no campo das ciências sociais. Um seleto grupo de corporações empresariais, ligado ao complexo da soja, cana-de-açúcar, milho, dentre outros cultivares, associado a interesses de empresas fornecedoras de defensivos agrícolas, produtos químicos, de toda sorte de produtos para aumento de produção no campo, bem como empresas de máquinas empregadas na produção agrícola, encontram, nos países pobres ou em vias de desenvolvimento, um amplo espectro de aplicação de seus capitais, apropriando-se de inúmeros benefícios. Tais benefícios vão desde a disponibilidade de terras até uma expressiva quantidade de homens e mulheres dispostos à fornecerem sua força de trabalho a baixos salários, passando pelo apoio do Estado no tocante ao financiamento de projetos, isenções de impostos, dentre outros benefícios.

"O Cerrado é o segundo maior bioma da América do Sul, ocupando uma área de 2.036 .448 km2, cerca de 22\% do território nacional. A sua área contínua incide sobre os estados de Goiás, Tocantins, Mato Grosso, Mato Grosso do Sul, Minas Gerais, Bahia, Maranhão, Piauí, Rondônia, Paraná, São Paulo e Distrito Federal, além dos encraves no Amapá, Roraima e Amazonas." (MINISTÉRIO DO MEIO AMBIENTE, 2014). Ver: mapa 1. 


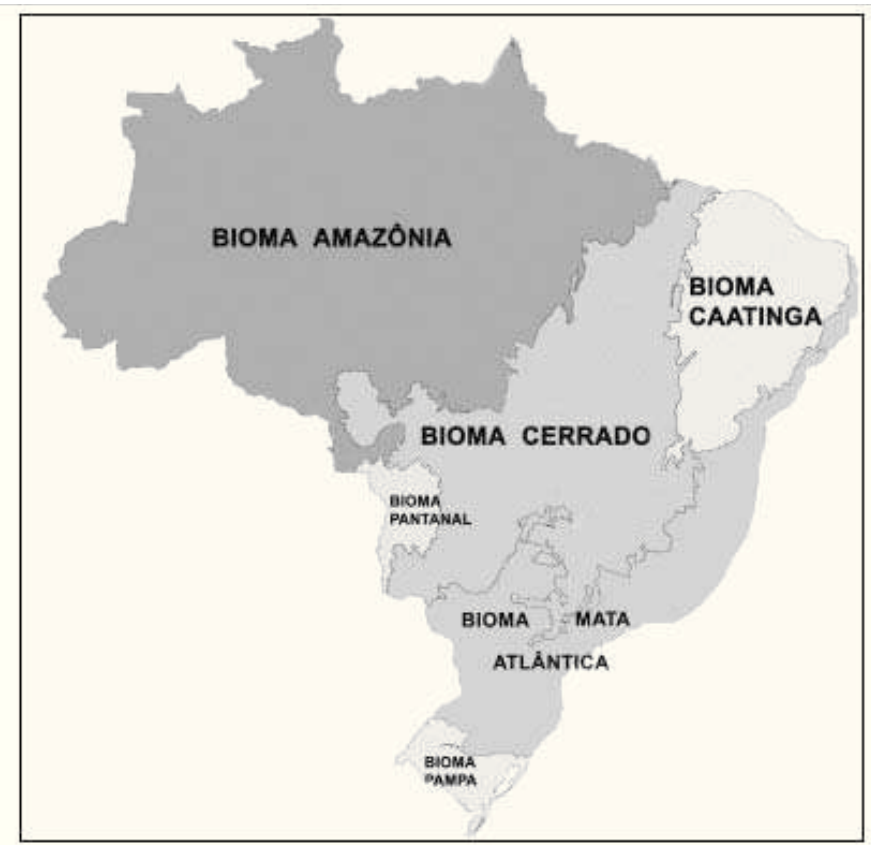

Mapa 1 - Bioma Cerrado

FONTE: IBGE, 2014.

HTTP://WWW.IBGE.GOV.BR/HOME/PRESIDENCIA/NOTICIAS/2 1052004 BIOMASHTML.SHTM

Destarte, essa geopolítica dos territórios e das atividades econômicas que tem como alvo os países do hemisfério sul aglutina interesses diversos, os quais estão ligados tanto ao capital dito produtivo quanto ao capital financeiro. No caso brasileiro ele pode ser apreendido por meio do deslindamento do chamado agronegócio, cujas atividades tem ocupado vastas extensões do território, promovendo violência sobre os povos. Nas reflexões do presente texto importa levar a termo tal fenômeno numa dupla perspectiva, a geopolítica, mas também a perspectiva sociocultural, uma vez que ambas estão associadas e a primeira se vale desta em seu processo de materialização. Noutros termos, o estabelecimento das atividades de agronegócio, associadas aos interesses dos complexos empresariais e mesmo bancos cujos capitais são de inúmeros países pertencentes ao hemisfério norte, ocorre sob algumas bases culturais e ideológicas que podem ser apreendidas a partir dos seguintes binômios: atrasado-moderno; arcaico-tecnológico; marginal-produtivo, dentre outros, mas também 
outros que fazem alusão ao plano eminentemente cultural: brancos-negros; bárbaros-civilizados; normais-exóticos.

Estes binômios não apenas sustentam a ofensiva sobremaneira europeia e norte-americana por sobre os países pobres, mas estão incrustados no seio das mentalidades, imantados no tecido social como referenciais para as representações coletivas. No limite, são eles que justificam e legitimam tal ofensiva, balizando a dominação econômica, cultural e simbólica. Assim, a violência de que trata este trabalho se institui não apenas nos desdobramentos econômicos que resultam do divórcio entre os povos e seus territórios, territórios nos quais são extraídas as fontes de subsistência, mas fundamentalmente nos desdobramentos atinentes à um plano subjetivo, o qual diz respeito à relação entre estes povos e os territórios na edificação de seus referenciais, valores, códigos culturais, portanto, dos elementos fundantes de suas existências. $\mathrm{Na}$ essência, esta violência se instaura a partir de relações totalmente assimétricas, as quais tem como substrato a abjeção do outro (índios, negros, povos tradicionais) e sua subordinação aos ditames do colonizador. Com efeito, àquele que é subordinado são negados os princípios básicos que conferem a condição humana, "[...] uma vez que ninguém pode sem crime espoliar seu semelhante, escravizá-lo ou matá-lo, eles dão por assente que o colonizado não é semelhante do homem." (SARTRE, 1968: 9). Sartre (1968, p: 9) acrescenta que:

A violência colonial não tem somente o objetivo de garantir o respeito desses homens subjugados: procura desumanizá-los. Nada deve ser poupado para liquidar as suas tradições, para substituir a língua deles pela nossa, para destruir a sua cultura sem lhes dar a nossa; é preciso embrutecê-los pela fadiga.

Nas décadas recentes, os povos cerradeiros têm sido, e recorrendo aos termos empregados por Sartre, subjugados, desumanizados. Cabe pensar estes processos sem promover a equivocada e sempre recorrente dissociação homem-natureza. Assim, a ferocidade empregada na derrubada de matas nativas, na ameaça à fauna e à flora também é o que media a relação homem-homem nos processos de espoliação de trabalhadores rurais, populações tradicionais e comunidades indígenas de seus territórios. $\mathrm{O}$ poder econômico das grandes empresas, aliado a um projeto de crescimento econômico a qualquer custo, aos interesses do capital produtivo, rentista $\mathrm{e}$ financeiro internacional, engendram fenômenos territoriais que remetem às mais sangrentas carnificinas da história humana. 
A quem tributar a responsabilidade? Tais processos e fenômenos se instituem via grandes corporações e projetos de estados-nações ávidos por mais lucro e mais poder. Trata-se do fundamentalismo do mundo moderno operado a partir das grandes empresas tendo em vista o fornecimento de toda sorte de mercadorias e a acumulação capitalista sob as mais variadas formas. Tudo se é permitido e facilitado no tocante à exploração dos recursos naturais nos países do sul quando o que interessa é o atendimento das demandas advindas de todos os cantos do planeta. É o que Harvey (2004) denomina de acumulação via espoliação. Aproveitar a abundância de terras, os recursos hídricos, as condições climáticas e vegetativas é o intento das grandes corporações a fim de, por um lado, fornecerem mercadorias mais baratas e, por outro, dominar territórios para além das fronteiras dos estados-nações sede. A ofensiva chinesa é, nesse particular, um exemplo emblemático.

No afã de obterem territórios para a expansão da produção de soja, cana-de-açúcar de demais commodities, tendo em vista o abastecimento de seus mercados e a concorrência internacional, imensas glebas de terras têm sido compradas por corporações estrangeiras, especialmente chinesas e europeias, ano após ano, sob os auspícios do Estado, o qual não apenas facilita tais operações, mas as concebe enquanto necessárias e indispensáveis para o progresso, dada a nossa suposta vocação natural para a produção de alimentos e criação de animais, especialmente nas regiões que conformam a chamada nova fronteira agrícola, compreendida por vastos territórios do bioma cerrado localizados nos estados de Goiás, Mato Grosso do Sul, Mato Grosso, Maranhão, Piauí, Tocantins e Bahia, de forma mais acentuada nos quatro últimos estados.

SOBRE O PODER E AS DINÂMICAS SOCIOTERRITORIAIS NO CERRADO BRASILEIRO

Tem-se que os constructos teóricos no âmbito do pensamento póscolonial $^{5}$ fornecem aportes para a reflexão e apreensão das dinâmicas socioterritoriais no Brasil. Tais escritos permitem apreender a dimensão

Segundo Barbosa (2012, p. 218): "Por pós-colonialismo se identifica um “grupo" específico de intelectuais do "Terceiro Mundo", que teriam ascendido às academias estadunidenses e europeias na década de 1980. Este "grupo" teria por objeto de estudo a crítica ao ocidentalismo e ao discurso colonial, mas o faria a partir da própria tradição europeia, retomando as perspectivas pós-estruturalistas contemporâneas. Costuma-se citar como integrantes deste "grupo", geralmente, os seguintes intelectuais: Edward Said (palestino), Gayatri Spivak (indiana) e Homi Bhabha (indiano).” 
social, psíquica, econômica, política e cultural da dominação que se faz exercida sobre os mais diversos povos, aqui denominados de subalternos. Assim, não importa ter como desiderato apenas a descrição de fenômenos de ordem econômica e seus desdobramentos sociais em termos de recrudescimento das disparidades materiais de existência e de uma relação desigual entre países centrais e periféricos, mas esmiuçar os processos de subalternização de determinados grupos sociais, problematizar como se operam os mecanismos de dominação numa dimensão psicossocial e, finalmente, apreender o sentido da violência numa ordem neocolonial.

Com efeito, essa démarche intelectual reserva um projeto político em que a emancipação dos sujeitos passa inexoravelmente pela subversão a partir da cultura. Nesse sentido é que as teorias pós-coloniais não se ocupam apenas da compreensão das novas dinâmicas de dominação, mas ensejam postulados a partir dos quais são abertas novas searas de reflexão e de posicionalidade dos agentes. A linguagem é central nesse projeto à medida que por meio dela se opera um projeto de subversão da ordem das coisas, ou seja, se é por meio dela que o domínio civilizado-bárbaro, nortesul, ocidente-oriente, branco-negro se faz exercido é nela fundamentalmente que reside um componente político e por ela é que se deve aquilatar as dinâmicas de poder a fim de rompê-las.

Compartilhar do debate pós-colonial consiste, em última instância, considerar que os saberes edificados cimentam e legitimam relações de poder e que, portanto, engendrar novas perspectivas analíticas - tendo como elemento axial uma ruptura epistêmica que em linhas gerais diz respeito ao rechaço às perspectivas eurocêntricas de explicação da realidade - não se reduz apenas à um propósito interpretativo, mas eminentemente político. Exatamente por isso a teoria pós-colonial possui significativa influência do chamado "desconstrutivismo francês", que tem, em Jacques Derrida, Michel Foucault, e Gilles Deleuze, seus principais nomes. É este o sentido do termo diffèrance empregado por Bhabha, assim como por outros pensadores pós-coloniais. Segundo Barbosa (2012: 224): "Estes o entenderiam como uma espécie de essência transgressora, para além da lógica dicotômica dos discursos."

As dinâmicas socioterritoriais que têm se estabelecido no âmbito do cerrado brasileiro conduzem as reflexões à processos mais amplos e complexos que, conforme enunciado, têm sido engendrados nos países latino-americanos, asiáticos e africanos por excelência. Tomemos o cerrado como microcosmo desses processos a partir de uma perspectiva em que os fenômenos socioterritoriais são entendidos em sua natureza social, histórica e 
prioritariamente cultural e antropológica. A violência cometida contra povos indígenas e populações tradicionais, em primeira instância, parece ter como resposta os interesses capitalistas advindos de grandes corporações empresariais. Numa análise mais detida, porém, o que exige o refinamento metodológico e conceitual - nesse particular a obra de Said constituiu um marco para o pensamento pós-colonial - só é possível apreender tal violência quando se leva em conta os parâmetros de comparação entre culturas e povos.

Vandana Shiva (2003), ao apontar o domínio dos países do "norte" sobre os do "sul", exercido por meio dos interesses econômicos de grandes grupos ligados ao mercado de agrotóxicos, defensivos agrícolas, enfim, produtos aplicados à produção agrícola tendo em vista aumento da produtividade, não fazia alusão apenas ao desejo dos primeiros em acumularem capital às expensas dos segundos, mas referia-se ao domínio que se faz exercido a partir das concepções de realidade e, portanto, dos saberes, dos conhecimentos desenvolvidos e aplicados. Exatamente por isso, segundo a intelectual e militante indiana, para além das monoculturas enquanto expressão de domínio dos territórios haveriam monoculturas da mente, em que são cultivados e reproduzidos conhecimentos segundo as premissas do pensamento europeu, os quais, longe de serem neutros e desinteressados, cumprem os ditames de uma dominação cultural à medida em que se tornam hegemônicos. Nesse sentido, com base na problematização dos saberes e da invizibilização/negação dos saberes do "sul", os escritos de Shiva (2003) nos remete àquilo que Said (1990: 51) identificou como força cultural, que, nas palavras do teórico:

"A forca cultural não é urna coisa que podemos discutir facilmente - e um dos objetivos do presente trabalho é ilustrar, analisar e refletir sobre o orientalismo como um exercício de forca cultural."

Porém, como o próprio Said coloca, não se pode generalizar sobre uma noção, segundo ele, tão vaga e tão importante como a de força cultural. Assegurado o devido cuidado no uso da expressão cunhada por Edward Said, entende-se que os fenômenos recentes no âmbito dos processos de ocupação dos territórios e espoliação das populações nativas e comunidades tradicionais nos países latino-americanos tem como substrato uma "força cultural". São processos que se instituem a partir de conhecimentos gestados nos grandes centros de pesquisas norte-americanos e europeus e que são levados a cabo por meio da negação de conhecimentos outros en- 
gendrados no seio das próprias comunidades, saberes seculares cujo cerne consiste numa relação homem-natureza em que o sentido não reside no domínio que àquele exerce sobre esta. Os conhecimentos hegemônicos, no entanto - uma vez que deslocados do lugar ao qual se voltam e se materializam em práticas (como as práticas agrícolas da chamada extensão rural) - necessitam de legitimação, de sorte que esta legitimação ocorre graças à tradições e instituições historicamente instituídas nos países colonizados. Segundo Said (1990: 33):

O valor, a eficácia, a forca e a aparente veracidade de urna declaração escrita sobre o Oriente, portanto, baseiam-se muito pouco no próprio Oriente, e não podem instrumentalmente depender dele como tal. Ao contrário, a declaração escrita é urna presença para o leitor em virtude de ter excluído, deslocado e tornado supérfluo qualquer tipo de "coisa autentica" como "o Oriente". Desse modo, todo o orientalismo está fora do Oriente, e afastado dele: que o orientalismo tenha qualquer sentido depende mais do Ocidente que do Oriente, e esse sentido é diretamente tributário das várias técnicas ocidentais de representação que tornam o Oriente visível, claro e "lá" no discurso sobre ele. E essas representações utilizam-se, para os seus eleitos, de instituições, tradições, convenções e códigos consentidos, e não de um distante e amorfo Oriente.

Mutatis mutandis, com base nos processos históricos de dominação colonial encetados pelos países europeus na América, é possível inferir que houve uma construção de representações particulares e idiossincráticas, portanto uma espécie de força cultural, sobre o território e os povos autóctones, especialmente na porção sul do continente. Contudo, não com o mesmo sentido da relação Europa - Oriente. O sociólogo peruano Aníbal Quijano, ao tratar dessa questão deslinda a lógica investida nas relações de dominação por parte dos colonizadores, apontando como a ideia de raça foi um meio para tal propósito. Quijano vai mais longe ao elucidar que as relações sociais de trabalho, e portanto os papéis sociais desempenhados pelos indivíduos nesse período, operavam-se segundo a classificação das raças. "As novas identidades históricas produzidas sobre a idéia de raça foram associadas à natureza dos papéis e lugares na nova estrutura global de controle do trabalho". (QUIJANO, 2005: 228). Com isto, observa que as teorizações sobre a relação centro-periferia, as quais tiveram considerável contribuição de Raúl Prebish, acabaram apontando para o núcleo da dinâmica de divisão do trabalho e acumulação capitalista, a saber, o eurocentrismo e as práticas coloniais. Conforme Quijano: "O capitalismo mundial foi, desde o início, colonial/moderno e eurocentrado." (2005: 230). 
Com efeito, a principal contribuição de Quijano está em que não se pode pensar os processos de colonização e de dominação econômica sem levar a termo as tessituras das relações de poder, cujo aspecto axial consiste no constructo da ideia de raça. Âs raças cabiam diferentes atividades, uma vez que distintas e hierarquicamente desiguais. Assim, tal constructo legitimava a inferiorização de negros e índios ao passo que naturalizava tais processos. Amiúde utilizada como elemento peremptório de distinção social, às raças sempre eram vinculadas a determinadas representações. Esta tornara-se a premissa universal de dominação social segundo Quijano. Atribuir a uma suposta determinação natural as clivagens operadas no seio das relações sociais é não apenas um fim, mas fundamentalmente um meio para o exercício da dominação exercida pelos colonizadores e que ecoam e são reverberadas em tempos hodiernos. Segundo Quijano (2005: 228):

$\mathrm{Na}$ América, a idéia de raça foi uma maneira de outorgar legitimidade às relações de dominação impostas pela conquista. A posterior constituição da Europa como nova identidade depois da América e a expansão do colonialismo europeu ao resto do mundo conduziram à elaboração da perspectiva eurocêntrica do conhecimento e com ela à elaboração teórica da idéia de raça como naturalização dessas relações coloniais de dominação entre europeus e não-europeus. Historicamente, isso significou uma nova maneira de legitimar as já antigas idéias e práticas de relações de superioridade/inferioridade entre dominantes e dominados. Desde então demonstrou ser o mais eficaz e durável instrumento de dominação social universal, pois dele passou a depender outro igualmente universal, no entanto mais antigo, o intersexual ou de gênero: os povos conquistados e dominados foram postos numa situação natural de inferioridade, e conseqüentemente também seus traços fenotípicos, bem como suas descobertas mentais e culturais. Desse modo, raça converteu-se no primeiro critério fundamental para a distribuição da população mundial nos níveis, lugares e papéis na estrutura de poder da nova sociedade. Em outras palavras, no modo básico de classificação social universal da população mundial.

A questão racial que fundamentou as relações de opressão e dominação por parte dos colonizadores é, conforme mostra Quijano (2005), um traço peculiar do processo de ocupação da América. Diferentemente da construção realizada em torno do oriente como o "outro", os "índios" da América, assim como os "negros" africanos sequer seriam referenciados como povos dotados de outras culturas, valores, referenciéis, mas raças inferiores, constituídas por "primitivos". Foi engendrada, assim, uma arraiga- 
da teia de dominação, a qual se ancorou nas representações sobre índios e negros, suas práticas sociais, seus conhecimentos a fim de deslegitimá-las e, pari passu, a isto foi reafirmado o domínio colonial e a supremacia racial branca, posicionando a Europa não apenas como centro econômico, mas, ipso facto, centro de produção e difusão do chamado conhecimento científico, berço da modernidade e do progresso, ao que foram atribuídas aos colonizados as seguintes adjetivações: primitivos, irracionais, retrógrados, atrasados, dentre outras. Sobre esta questão, Quijano (2005: 231) afirma:

Em primeiro lugar, expropriaram as populações colonizadas -entre seus descobrimentos culturais - aqueles que resultavam mais aptos para o desenvolvimento do capitalismo e em benefício do centro europeu. Em segundo lugar, reprimiram tanto como puderam, ou seja, em variáveis medidas de acordo com os casos, as formas de produção de conhecimento dos colonizados, seus padrões de produção de sentidos, seu universo simbólico, seus padrões de expressão e de objetivação da subjetividade. [...]Todo esse acidentado processo implicou no longo prazo uma colonização das perspectivas cognitivas, dos modos de produzir ou outorgar sentido aos resultados da experiência material ou intersubjetiva, do imaginário, do universo de relações intersubjetivas do mundo; em suma, da cultura.

Sem o domínio que se fez exercido a partir da cultura, o projeto de exploração econômica dos recursos disponíveis, bem como a submissão de índios e negros aos piores trabalhos, não teria logrado êxito. Com base nas reflexões aqui apontadas, entende-se que fenômenos recentes de ocupação de áreas do bioma cerrado só podem ser devidamente apreendidos considerando o sentido investido nessa lógica de dominação, ou seja, a colonialidade do poder que esteia a ofensiva capitalista recente e que incorre em resultados extremamente deletérios às populações indígenas e tradicionais. Por outro lado, é premente discutir essa colonialidade do poder no âmbito das disputas territoriais e a criminalização dos movimentos sociais, bem como a colonialidade do poder exercida por uma instância político-institucional que tem, reiteradas vezes, deixado de reconhecer os direitos dessas populações.

Debates recentes em torno da demarcação das terras indígenas, quilombolas e demais comunidades tradicionais ilustram bem essa questão. A proposição da Proposta de Emenda Constitucional (PEC) 215/ $2000^{6}$ que transfere, para o poder legislativo, a prerrogativa de deliberar

6 Disponivel em:http://imagem.camara.gov.br/Imagem/d/pdf/DCD19ABR2000.pdf\#page=69 
sobre a política das terras indígenas aponta para uma estratégia em que a colonialidade do poder é demarcada a partir da crítica que se faz à fragilidade atual dessa política. Em pormenores, integrantes do poder Legislativo reivindicam a aprovação da PEC alegando que antropólogos contratados pela Fundação Nacional do Indio (FUNAI) não seriam criteriosos e tampouco neutros nos processos decisórios. A principal justificativa consiste na necessidade de se descentralizar essa política, transferindo a responsabilidade para outras esferas do poder.

A estratégia poder-saber, conforme definiu Foucault (2012), é aqui destacada para se referir, por um lado, ao apelo institucional para a tomada de decisões que atingem interesses econômicos históricos, como o monopólio da terra e, nas últimas décadas, os interesses ligados ao agronegócio e, por outro, à crítica ao saber antropológico e aos intelectuais. Ainda que tal estratégia não faça referência à "força cultural" de brancos sobre negros e índios, é esta força que encontra-se no âmago da proposta.

Ou seja, a institucionalização e a judicialização das questões encobrem, velam, as relações de poder e, por seu turno, a violência conformada pelas disputas territoriais entre, de um lado grandes proprietários de terras, advindos de uma elite agrária branca, e, de outro, índios e negros, historicamente alijados de direitos, ainda aludidos como inferiores, primitivos. Não obstante a colonialidade do poder esteja sendo operada de forma sutil e estrategicamente velada, é possível observar que tem sido vertiginosa sua presença nas últimas décadas nos países latino-americanos. É óbvio que em cada país isto se sucede sob determinadas condições. Sobre isto, Quijano (2005: 275) afirma que:

O que pudemos avançar e conquistar em termos de direitos políticos e civis, numa necessária redistribuição do poder, da qual a descolonização da sociedade é a pressuposição e ponto de partida, está agora sendo arrasado no processo de reconcentração do controle do poder no capitalismo mundial e com a gestão dos mesmos responsáveis pela colonialidade do poder. Conseqüentemente, é tempo de aprendermos a nos libertar do espelho eurocêntrico onde nossa imagem é sempre, necessariamente, distorcida. É tempo, enfim, de deixar de ser o que não somos.

Estas populações vivem nas mais diversas áreas do cerrado brasileiro. São indígenas, quilombolas, vazanteiros (povos ribeirinhos que vivem no cerrado às margens dos rios São Francisco, Tocantins e Araguaia), geraizeiros (moradores do cerrado ao norte de Minas Gerais), quebradeiras de coco e pequenos agricultores. Elas têm, em comum, a relação com a 
terra, cujo sentido não é o de uma mercadoria, mas fonte de sobrevivência tanto na acepção material quanto na simbólica, cultural, cosmogônica. $\mathrm{O}$ conhecimento eurocêntrico, calcado nas premissas da racionalidade e tido por moderno e indispensável para o progresso, torna-se estratégia podersaber à medida em que é colocado num plano de superioridade em relação aos demais saberes. Assim, o conhecimento dos brancos, ao suplantar os conhecimentos dos negros e índios, promove a violência em sua instância elementar, a negação do outro a partir de suas crenças, valores, perspectivas de realidade, em suma, sua relação com a natureza e com os seus iguais.

A violência contra povos indígenas e comunidades tradicionais no cerrado contribui de forma significativa para o alcance do conceito de território como categoria analítica e interpretativa, tornando-se condição basal para o entendimento da construção identitária desses segmentos socioculturais. A lógica imputada pelas grandes empresas capitalistas no Cerrado, diretamente recoloca a discussão em um outro campo epistemológico, uma vez que, as histórias, as lutas por garantias territoriais e identitárias perpassam por relações que se estabelecem no tempo e no espaço que foram construídos por ações coloniais. Esse estudo no campo interdisciplinar possibilita uma compreensão das e sobre as colonialidades de poder, asseverando uma análise crítica que tem como propósito romper com as concepções de uma temporalidade teleológica ou linear, ou ainda revisitar teorias que apresentam o espaço pós-colonial, em uma perspectiva vetorial unívoca (Europa- Américas; África - Brasil; Ásia- Europa, dentre outras). O território como categoria interpretativa assente em uma visão pós-colonial privilegia a compreensão do "espaço existencial do humano" (SOJA, 1993), que se constrói por diversas formas e possibilidades de vivências, em acordo com subjetividades, sensibilidades e pertencimento, sobretudo com outros espaços e tempos. Destarte, a violência torna-se a herança dos ditos processos coloniais que imputaram mecanismos de subalternização e que, na atualidade, concedem abertura ao debate com outras formas de saberes na busca da descolonização das culturas, das crenças, das paisagens e dos territórios.

A ocupação do cerrado brasileiro, indiscutivelmente, está alicerçada em ações e construções culturais que negaram os princípios de diferença e alteridade e, ainda reforçou a ideia de que a violência é produto de forças históricas e geográficas específicas que se fizeram por modos de representações dominantes, perpetuadas por estratégias de exclusão e dominação das culturas e dos lugares colonizados - as colonialidades de poder. 
Nesse ínterim, o conceito de colonialidade de poder relaciona-se por meio da crítica às questões que promulgam heranças coloniais que ainda se fazem presentes nas sociedades contemporâneas, em especial nas nações subdesenvolvidas. Nesses espaços, os modelos coloniais se reproduzem pelos mecanismos do modelo europeu de sociedade, de produção e de experiências diluídas em cotidianos que já refletem o ordenamento e a disciplinarização da vida. O argumento de Quijano (2005) abarca as ações e relações de dominação sobrepostas em locais nos quais as hierarquias sociais foram organizadas tomando por base os construtos étnicos, raciais e socioculturais.

As singularidades dos saberes locais foram submersas pela ação colonizadora em um sentido lato. Acrescenta-se a ideia de que o espaço geográfico foi redefinido para além de limites e fronteiras físicas. A ação colonizadora incluiu uma nova ordem nas dimensões simbólicas e epistemológicas. Seu principal desdobramento é a violência que se materializa nos processos de desterritorialização vivenciados pelas populações, resultando em agressões físicas e assassinatos de índios, negros e pequenos produtores rurais. $\mathrm{O}$ cerrado tem sido palco de intensos conflitos dessa natureza. Contudo, uma teia de poder que envolve interesses do capital ligado à produção agrícola, ao capital financeiro, aos grandes proprietários de terras, dentre outros, opera no sentido de criminalizar os movimentos sociais de luta pela terra e impedir o reconhecimento de direitos de comunidades, como as indígenas e quilombolas. Os arranjos políticos extrapolam a seara do parlamento e mobilizam entidades patronais cujos discursos e posicionamentos são altamente reacionários, conservadores e violentos. É construída, assim, uma retórica de classe cujos pilares discursivos tem em vista deslegitimar a luta dessas populações. $\mathrm{O}$ projeto de ruptura com a colonialidade do poder passa inexoravelmente pela desconstrução desse discurso, pela defesa dos direitos das minorias, pelo reconhecimento de suas culturas e de seus territórios.

\section{BREVES CONCLUSÕES}

Os recentes processos de desterritorialização de populações indígenas, comunidades tradicionais e pequenos produtores rurais no cerrado fornecem uma espécie de síntese do neocolonialismo e da violência que tem se abatido sobre as populações tradicionais nos países latino-americanos. Interesses econômicos, ligados à grandes corporações europeias, estadunidenses, chinesas, dentre outras nacionalidades, têm promovido al- 
terações substanciais nos territórios brasileiros e de outros países pobres ou em vias de desenvolvimento. Compreender tais processos exige, no entanto, um refinamento e uma vigilância intelectual e analítica. Cumpre considerálos enquanto manifestação de uma nova dinâmica colonial, a qual se ancora fundamentalmente na negação/inferiorização de povos e seus saberes, seus valores, sua cultura.

No cerrado, populações indígenas, quilombolas, vazanteiros, geraizeiros, dentre outras, bem como pequenos produtores rurais têm sido vitimados pela expansão de monoculturas, especialmente, soja e cana-deaçúcar, mas também pela instalação de grandes projetos de exploração de minérios e hidroelétricos. Entende-se que estes fenômenos, além de econômicos, uma vez que o aumento da produção de commodities tem como objetivo o mercado internacional e a obtenção de superávits na Balança Comercial, são eminentemente culturais, pois que resultantes de um domínio que historicamente se faz exercido por brancos dos países do norte sobre negros e índios dos países do sul.

Com efeito, o pensamento pós-colonial apresenta um fecundo cipoal de reflexões sobre as relações de poder e domínio a partir dos ditames da cultura. Ele reserva, para além de construções teóricas a partir de diversas realidades históricas investigadas por seus principais nomes, um sentido político, em que o alcance de direitos passa pela afirmação dos saberes tradicionais. Destarte, não cabe apenas a elaboração crítica das empreendidas econômicas advindas de grandes corporações financeiras e empresariais, mas a reivindicação de espaços nas arenas decisórias e, no que tange o conhecimento, a ruptura com a perspectiva eurocêntrica da nossa realidade. Tal projeto consiste em garantir a existência de múltiplas visões sobre a existência e sobre a natureza à medida em que se tem por claro e inequívoco que o chamado conhecimento racional, hegemônico no ocidente e difundido pela Europa, orientou-se para a dominação de índios e negros, violentando-os tanto do ponto de vista cultural quanto do ponto de vista econômico, do que este não far-se-ia plena e efetivamente empreendido sem àquele.

\section{REFERÊNCIAS BIBLIOGRÁFICAS}

BARBOSA, Muryatan Santana. Homi Bhabha leitor de Frantz Fanon: Acerca da prerrogativa póscolonial. Revista Crítica Histórica. Ano III, nº 5. p. 217-231, 2012.

CÂMARA DOS DEPUTADOS. Proposta de Emenda à Constituição N. ${ }^{\circ} 215$, de 2000. Diário da Câmara dos Deputados. p. 69-78. Disponível em: http://imagem.camara.gov.br/Imagem/d/pdf/ DCD19ABR2000.pdf\# page=69. Consultado em 14 nov. 2014. 
FOUCAULT, Michel. Ditos e escritos, volume IV: estratégia, poder-saber. Rio de Janeiro: Forense Universitária, 2012.

HARVEY, David. O novo imperialismo. São Paulo: Edições Loyola, 2004.

IBGE - Instituto Brasileiro de Geografia e Estatística. Masas de biomas e de vegetação. Disponível em: http://www.ibge.gov.br/home/presidencia/noticias/21052004biomashtml.shtm. Acesso em: 02 jan. 2015. MINISTÉRIO DO MEIO AMBIENTE. O bioma cerrado. Disponível em: http://www.mma.gov.br/ biomas/cerrado. Consultado em: 29 nov. 2014.

QUIJANO, Aníbal. Colonialidade do poder, eurocentrismo e América Latina. En libro: A colonialidade do saber: eurocentrismo e ciências sociais. Perspectivas latino-americanas. Edgardo Lander (org.). Colección Sur Sur, CLACSO, Ciudad Autónoma de Buenos Aires, Argentina, pp. 227-278, 2005. Disponível em: http://bibliotecavirtual.clacso.org.ar/ar/libros/lander/pt/Quijano.rtf. Consultado em 15 set. 2014.

SAID, Edward. Orientalismo: O oriente como invenção do ocidente. São Paulo: Companhia das Letras, 1990.

SARTRE, Jean Paul. Prefácio. Os condenados da terra, de Frantz Fanon. Rio de Janeiro: Civilização Brasileira, 1968.

SHIVA, Vandana. Monoculturas da mente: Perspectivas da biodiversidade e da biotecnologia. São Paulo: Gaia, 2003. 